\title{
PERBAIKAN KUALITAS KERJA DENGAN DESAIN ALAT PENOPANG KEPALA BAGI BURUH SUWUN DI PASAR BADUNG DENPASAR
}

\author{
I Made Bulda Mahayana
}

\begin{abstract}
One side of industrialization have followed the progress of science and technology in the formal workers, informal workers the other hand very little attention from the government, such as suwun workers lift transport of goods in the Market Badung, Denpasar. The purpose of research is to identify the workload and subjective complaints suwun workers before and after using the tool supporting head in the Market Badung, Denpasar. This type of research is pre experiment with the same study design subject of a pattern of "One Group Pretest-Posttest Design". Large sample of 14 persons. The results of the research work environment temperatures between $30-32^{\circ} \mathrm{C} ; 80-87 \%$ humidity and wind speed ranges between $10-$ $14 \mathrm{~km} / \mathrm{h}$. A decline in the average value of the pulse rate of $5.47 \%$ of the workers suwun who use braces head with the tool supporting that do not use the head and there are differences in the pulse of work before and after using the tool supporting head ( $p<0.05)$. A decline in the average value of subjective complaints $11.43 \%$ suwun workers who use the tool supporting head with do not use the the tool supporting head and there are differences in subjective complaints before and after using the tool supporting head ( $p<0.05$ ). Conclusion No difference pulse work and subjective complaints suwun workers at Market Badung Denpasar before and after using the tool supporting head. Advice to the parties concerned to continue to disseminate to the workers suwun about the benefits derived from the use of tools supporting the head and the other researchers in order to create a more the tool supporting head inovasif and modern.
\end{abstract}

Keywords : the tool supporting head, workload, subjective complaints

\section{PENDAHULUAN}

Pembangunan industrialisasi dan

mekanisasi telah tumbuh dan

berkembang seiring dengan kemajuan

ilmu pengetahuan dan teknologi.

Pertumbuhan industri yang pesat tanpa

disertai dengan upaya pengamanan

efek samping penerapan teknologi akan menimbulkan berbagai masalah kesehatan dan keselamatan kerja yang ditandai dengan meningkatnya prevalensi penyakit akibat kerja, keracunan, kecelakaan kerja, cacat bahkan kematian. Satu sisi industrialisasi dan mekanisasi telah 
mengikuti kemajuan ilmu pengetahuan dan teknologi pada pekerja formal, namun sisi lain pekerja informal sangat kecil memperoleh perhatian dari pemerintah seperti kuli panggul. Kuli panggul merupakan pekerja yang bekerja dengan menjual jasa mengangkut barang dari satu tempat ke tempat yang lain. Pada umumnya, pekerjaan tersebut menggunakan manual handling ${ }^{1}$. Sedangkan pekerja angkat-angkut barang pada pasar tradisional di Bali disebut "buruh suwun" mereka selalu merasakan keluhan subjektif yaitu berupa kelelahan pada saat dan setelah bekerja. Keluhan pada muskuloskeletal telah menjadi trend penyakit terbaru berkaitan

dengan pekerjaan di seluruh dunia baik di negara berkembang maupun negara industri

2. Lelah ini terjadi disebabkan karena adanya kontraksi otot-otot yang tidak perlu atau tidak memiliki hubungan langsung atau karena adanya kontraksi otot statis. Suatu sistem kerja yang tidak dirancang dengan baik, juga tidak berdasarkan kaidah-kaidah ergonomi. Hal ini dapat memicu lebih dini timbulnya kelelahan, gangguan muskuloskeletal, beban kerja meningkat, mekanisme kerja menjadi tidak efektif dan efisien yang pada akhirnya akan menurunkan produktivitas pekerja. Buruh suwun dalam melakukan pekerjaan mengangkut dan memindahkan barang, bertumpu pada kepala dan leher serta dibantu dengan alat gerak lainnya seperti tangan untuk memegang wadah barang dan kaki untuk berpindah. Sistem kerja ini bila dilakukan berlebihan pekerja sering mengalami cedera, yakni: kerusakan pada diskus invertebralis yang menyebabkan rasa nyeri, ngilu, kelelahan berlebihan dan gangguan pada otot bagian kepala dan leher.

Buruh dalam melakukan pekerjaannya selalu memanfaatkan tenaga yang dibutuhkan untuk mengangkat barang sehingga kurang efisien, hal ini disebabkan karena keranjang mempunyai diameter terlalu besar sehingga jarak antara posisi gaya berat pengangkut dan gaya berat yang diangkut semakin jauh, akibatnya momen bertambah besar ${ }^{3}$ 
Pendapat lain menyatakan bahwa pekerjaan angkat angkut di pasar merupakan pekerjaan yang dilakukan secara manual. Pekerjaan ini meliputi pengangkatan dan penurunan barang. Aktifitas kerja pekerja tersebut berisiko untuk mengalami keluhan muskuloskeletal, karena kegiatan angkat angkut tersebut dilakukan secara manual yang dapat berisiko terjadinya keluhan muskuloskeleta ${ }^{4}$.

Berdasarkan pengamatan pendahuluan di Pasar Badung Denpasar hasilnya menunjukkan bahwa semua buruh suwun dalam

\section{METODE PENELITIAN}

Jenis penelitian ini Pra Eksperimen dengan rancangan penelitian sama subjek dan tidak ada kelompok pembanding (kontrol) menggunakan pola "One Group Pretest - Postest Design" 5. Lokasi penelitian ini dilaksanakan di Pasar Badung Kota Denpasar. Populasi penelitian adalah semua buruh suwun perempuan yang bekerja di Pasar Badung Denpasar dan Besar sampel sebanyak 14 orang. bekerja mengangkut barang dilakukan dengan cara meletakkan barang dan wadahnya di kepala. Setelah selesai mengangkut barang sering mengalami keluhan subjektif, seperti sakit atau nyeri pada kepala bagian atas, pegalpegal pada leher dan cepat merasakan kelelahan. Untuk mengurangi keluhan subjektif dan beban kerja dengan cara meningkatkan kinerja buruh suwun dapat dilakukan dengan memperbaiki kualitas kerja, seperti: sikap kerja, metode kerja, beban kerja dan desain alat kerja.

Analisis data terkait dengan umur, pendidikan, pengalaman kerja, berat badan dan antropometri dilakukan analisis statistik deskriptif. Sedangkan analisis statistik untuk mengetahui ada tidaknya perbedaan kinerja berdasarkan pendekatan denyut nadi pada saat istirahat maupun saat bekerja dan keluhan subjektif yang dirasakan oleh buruh suwun sebelum dan sesudah menggunakan alat penopang kepala dalam melaksanakan pekerjaan menggunakan uji Paired $t$ test. Tetapi dengan syarat diawali dengan melakukan $U j i-K S$ dimana uji 
ini dipergunakan untuk mengetahui normalitas data yang diperoleh dalam penelitian.

\section{HASIL}

1. Karakteristik subjek penelitian : a. Umur kisaran umur $\leq 35(50 \%)$ dan $\geq$ 35 tahun $(50 \%)$; b. Pendidikan SMP $(21,43 \%)$ dan SD $(78,57 \%) ; c$. Pengalaman kerja $\leq 15$ tahun $(78,57 \%)$ dan $>15$ tahun $(21,43 \%)$;

d. Berat badan $\leq 55 \mathrm{~kg}(50 \%)$ dan $>$ $55 \mathrm{~kg}(50 \%)$.

\section{e. Antropometri}

Antropometri subjek mengacu pada antropometri kepala orang Indonesia ${ }^{6}$, sebagai rujukan untuk mendesain alat penopang kepala. Sedang pengukuran dilakukan dari puncak bahu ke puncak kepala, diperoleh jarak $\leq 25 \mathrm{~cm}(78,57 \%)$ dan $\geq 25 \mathrm{~cm}(21,43 \%)$.

\section{Lingkungan kerja}

Pengukuran kondisi lingkungan kerja sesi pertama, pada saat subjek tanpa menggunakan alat penopang kepala, diperoleh kisaran suhu udara $30-32^{\circ} \mathrm{C}$; kelembaban $83-87 \%$ dan kecepatan angin kisaran antara 10-13 km/jam. Pengukuran kondisi lingkungan kerja sesi kedua, pada saat subjek menggunakan alat penopang kepala, diperoleh suhu udara $30-31^{\circ} \mathrm{C}$ ; kelembaban 80-85\% dan kecepatan angin kisaran antara 11-14 km/jam.

\section{Tanpa menggunakan alat} penopang kepala

a. Beban kerja

Beban kerja dengan pedekatan denyut nadi istirahat dan denyut nadi kerja menggunakan analisis statistik uji paired samples statistics hasil pengukuran denyut nadi istirahat subjek sebelum bekerja diperoleh rerata 81,43 denyut/menit, sedangkan hasil pengukuran denyut nadi kerja subjek sesudah bekerja diperoleh rerata 85,64 denyut/menit. Selanjutnya untuk mengetahui hubungan denyut nadi istirahat sebelum bekerja dengan denyut nadi kerja sesudah bekerja, maka dilakukan uji paired samples correlation diperoleh hasil sebesar 0,987 karena $\alpha=0,05>\operatorname{sig}=0,000$ berarti ada hubungan signifikan. Untuk mengetahui perbedaan denyut nadi istirahat sebelum bekerja dengan denyut nadi kerja sesudah bekerja, menggunakan uji paired samples test 
diperoleh hasil $\alpha=0,05>\operatorname{sig}$ (2-tailed)

$=0,000$ atau $(\mathrm{p}<0,05)$.

b. Keluhan subjektif

Menggunakan analisis statistik uji paired samples statistics hasil wawancara menanyakan keluhan subjektif yang dirasakan oleh subjek sebelum kerja diperoleh rerata 15,00 $\%$, sedangkan keluhan subjektif yang dirasakan oleh subyek sesudah kerja diperoleh rerata $27,86 \%$. Selanjutnya untuk mengetahui hubungan keluhan subjektif yang dirasakan dari subjek sebelum dan sesudah bekerja, maka dilakukan uji paired samples correlation diperoleh hasil sebesar 0,715 karena $\alpha=0,05>\operatorname{sig}=0,004$ berarti ada hubungan signifikan. Untuk mengetahui perbedaan keluhan subjektif dari subjek sebelum dan sesudah kerja, dengan menggunakan uji paired samples test diperoleh hasil $\alpha=0,05>\operatorname{sig}(2$-tailed $)=0,000$ tau $(\mathrm{p}<0,05)$. Jadi ada peningkatan keluhan yang dialami subjek secara signifikan sesudah melakukan pekerjaan.

\section{Tanpa dan dengan menggunakan alat penopang kepala}

a. Beban kerja

Beban kerja dengan pendekatan denyut nadi kerja menggunakan analisis statistik uji paired samples statistics hasil pengukuran denyut nadi kerja subjek sebelum menggunakan alat penopang kepala diperoleh rerata 86,14 denyut/menit, sedangkan hasil pengukuran denyut nadi kerja subjek sesudah menggunakan alat penopang kepala diperoleh rerata 81,43. Selanjutnya untuk mengetahui hubungan denyut nadi kerja sebelum dan sesudah menggunakan alat penopang kepala, maka dilakukan uji paired samples correlation diperoleh hasil sebesar 0,877 karena $\alpha=0,05$ > sig $=0,000$ berarti ada hubungan signifikan. Untuk mengetahui perbedaan denyut nadi kerja sebelum dan sesudah menggunakan alat penopang kepala dengan menggunakan uji paired samples test diperoleh hasil $\alpha=0,05>\operatorname{sig}$ (2-tailed) $=0,000$ atau $(\mathrm{p}<0,05)$. Jadi ada penurunan denyut nadi kerja subjek sesudah menggunakan alat penopang kepala dalam bekerja sebesar 5,47\%. 
b. Keluhan subjektif

Menggunakan analisis statistik diperoleh rerata keluhan subyektif $27,86 \%$, sedangkan hasil wawancara terkait keluhan subjektif yang dirasakan oleh subjek sesudah menggunakan alat penopang kepala diperoleh rerata 16,43 . Selanjutnya untuk mengetahui hubungan keluhan subjektif yang dirasakan dari subjek sebelum dan sesudah melakukan pekerjaan menggunakan alat penopang kepala, maka dilakukan uji paired samples correlation diperoleh hasil sebesar 0,761 karena $\alpha=0,05>$ sig $=$ 0,002 berarti ada hubungan signifikan. Untuk mengetahui perbedaan keluhan subjektif sebelum dan sesudah bekerja menggunakan alat penopang kepala, dengan uji paired samples test diperoleh hasil $\alpha=0,05>\operatorname{sig}$ (2-tailed) $=0,000$ atau $(\mathrm{p}<0,05)$. Jadi ada penurunan nilai rerata keluhan yang dirasakan subjek sesudah menggunakan alat penopang kepala dalam bekerja sebesar 11,43\%.

\section{PEMBAHASAN}

Hasil pengukuran kondisi lingkungan kerja untuk sesi pertama diperoleh suhu $\quad 30-32^{\circ} \mathrm{C}$; kelembaban $83-87 \%$ dan kecepatan angin kisaran antara 10-13 km/jam. Selanjutnya sesi kedua diperoleh suhu udara $30-31{ }^{\circ} \mathrm{C}$; kelembaban antara 80-85\% dan kecepatan angin kisaran antara 11-14 km/jam. Hasil pengukuran kondisi lingkungan kerja pada kedua sesi tersebut termasuk kategori aman, karena kondisinya lebih rendah dari batas toleransi yang direkomendasikan untuk negara dengan musim seperti Indonesia, yaitu suhu tinggi sebesar $35-40^{\circ} \mathrm{C}$, kelembaban antara $\quad 40-90 \%$ dan kecepatan angin kisaran antara 0,1-0,2 $\mathrm{m} / \mathrm{dt}$. Dengan demikian lingkungan kerja dalam penelitian ini telah memenuhi syarat kesehatan kerja dan menurunkan keluhan subjektif dalam melaksanakan pekerjaannya .

\section{Beban kerja}

Pengukuran sesi pertama denyut nadi istirahat sebelum bekerja diperoleh rerata 81,43 denyut/menit, sedangkan sesudah kerja diperoleh denyut nadi kerja rerata 85,64 
denyut/menit. Selanjutnya hasil analisis data denyut nadi istirahat sebelum bekerja dan denyut nadi kerja sesudah subjek melakukan pekerjaan, menggunakan uji paired samples test diperoleh hasil $\alpha=0,05>\operatorname{sig}$ (2-tailed) $=0,000$ atau $(\mathrm{p}<0,05)$. Sedangkan hasil pengukuran denyut nadi kerja pada sesi kedua sebelum menggunakan alat penopang kepala diperoleh rerata 86,14 denyut/menit, sedangkan denyut nadi sesudah menggunakan alat penopang kepala diperoleh rerata 81,43 denyut/menit. Selanjutnya hasil analisis denyut nadi kerja sebelum dan sesudah menggunakan alat penopang kepala dalam bekerja, dengan menggunakan uji paired samples test diperoleh hasil $\alpha=0,05>\operatorname{sig}$ (2-tailed) $=0,000$ atau $(\mathrm{p}<0,05)$.

Nilai denyut nadi tersebut termasuk dalam kategori beban kerja ringan, hal ini kemungkinan besar disebabkan karena jumlah subyek tergolong kecil $(n=14)$ dan pembatasan berat beban ditentukan sebesar $30 \mathrm{~kg}$, berpindah angkut sejauh 30 meter pada lantai datar. Namun demikian, secara kualitas ada penurunan nilai rerata denyut nadi kerja subjek yang bekerja tanpa menggunakan alat penopang kepala dengan nilai rerata denyut nadi kerja subjek yang bekerja menggunakan alat penopang kepala, yaitu penurunannya sekitar 5,47\%. Hal ini disebabkan karena subjek yang menggunakan alat penopang kepala beban tidak lagi pada kepala dan leher, tetapi bertumpu pada bahu kiri dan kanan. Hasil penelitian lain menyatakan bahwa terjadi penurunan denyut nadi kerja pekerja setelah dilakukan perbaikan terhadap sikap kerja dengan menggunakan meja dan kursi sesuai dengan antropometri pekerjanya ${ }^{7}$. Perbaikan stasiun kerja dan sikap kerja dapat menurunkan keluhan subjektif berupa gangguan otot skeletal secara signifikan ${ }^{8}$. disamping itu sikap kerja juga mempunyai pengaruh yang positif dengan keluhan subjektif ${ }^{9}$

Kondisi fisiologi para buruh angkat-angkut tradisional sebelum dan sesudah perlakuan adalah sama. Sedangkan frekuensi denyut nadi kerja pada sebelum dan sesudah perlakuan terjadi perbedaan secara bermakna dimana beban kerja buruh angkatangkut tradisional sebelum dan 
sesudah perlakuan berbeda secara signifikan $^{3}$.

Penilaian beban kerja yang berkaitan dengan kapasitas kerja dapat dilakukan dengan mengukur frekuensi denyut nadi kerja yang berhubungan linear dengan asupan oksigen maksimum. Semakin tinggi aktivitas tubuh menyebabkan metabolisme tubuh semakin meningkat sehingga kebutuhan $\mathrm{O}^{2}$ semakin besar ${ }^{10}$.

\section{Keluhan subjektif}

Kelompok tenaga pengangkut barang dengan cara meletakkan barang bawaannya di atas kepala di Bali dikenal dengan "buruh suwun". Kondisi jalan dan konstruksi bangunan serta perilaku penjual dan pembeli pada pasar tradisional seperti Pasar Badung Denpasar tidak memungkinkan konsumen mengunakan kereta dorong untuk memindahkan barang-belanjaannya. Kondisi tersebut konsumen menjatuhkan pilihan dengan menggunakan tenaga buruh suwun sebagai alternatif utama untuk memindahkan barang ke tempat tujuan. Buruh suwun dalam melaksanakan pekerjaannya mengandalkan kerja muskuluskeletal seperti otot : leher, bahu, lengan, tangan, punggung, pinggang, panggul, pantat, paha dan betis. Pekerjaan jenis ini membuat buruh suwun setelah bekerja memindahkan barang milik konsumen akan merasakan keluhan pada mukuluskeletal meningkat, fenomena ini dikategorikan sebagai keluhan subjektif akibat kerja. Peneliti lain menyebutkan bahwa kalau pekerja buruh angkat angkut memiliki status gizi yang baik, maka kebutuhan energi untuk otot terpenuhi dan bisa melakukan aktivitas kerja walaupun yang bersakutan perokok ${ }^{11}$.

Dalam penelitian ini selain diteliti mengenai keluhan subjektif juga diteliti mengenai beban kerja yang diperoleh dengan cara pengukuran denyut nadi buruh suwun sebelum dan sesudah melakukan pekerjaan. Setelah beristirahat selama dua hari dilanjutkan dengan pengukuran denyut nadi dan keluhan subjektif yang dirasakan oleh buruh suwun sebelum dan sesudah menggunakan alat penopang kepala dalam melakukan pekerjaannya. 
Dari hasil analisis data keluhan subjektif berupa gejala sakit pada : leher, bahu, lengan, tangan, punggung, pinggang, panggul, pantat, paha dan betis. Dijelaskan bahwa hasil pengumpulan data sesi pertama tanpa mengenakan alat penopang kepala, keluhan subjektif yang dirasakan subjek memperoleh rerata $15,00 \%$ dan $27,86 \%$. Selanjutnya untuk mengetahui hubungan keluhan subjektif yang dirasakan dari subjek sebelum dan sesudah bekerja, maka dilakukan uji paired samples correlation diperoleh hasil sebesar 0,761 karena $\alpha=0,05>\operatorname{sig}=0,004$ berarti ada hubungan signifikan. Untuk mengetahui perbedaan keluhan subjektif dari subjek sebelum dan sesudah bekerja, dengan menggunakan uji paired samples test diperoleh hasil $\alpha=0,05>\operatorname{sig}(2$-tailed $)=0,000$ atau $(\mathrm{p}<0,05)$.

Hasil pengumpulan data keluhan subjektif sesi kedua diperoleh rerata $27,86 \%$ dan $16,43 \%$. Selanjutnya untuk mengetahui apakah terdapat hubungan keluhan subjektif yang dirasakan dari subjek sebelum dan sesudah melakukan pekerjaan menggunakan alat penopang kepala, maka dilakukan uji paired samples correlation diperoleh hasil sebesar 0,682 karena $\alpha=0,05>\operatorname{sig}=0,007$ berarti ada hubungan signifikan. Untuk mengetahui apakah perbedaan keluhan subjektif dari subjek sebelum dan sesudah melakukan pekerjaan menggunakan alat penopang kepala, dengan uji paired samples test diperoleh hasil $\alpha=0,05>\operatorname{sig}$ (2-tailed) $=0,000$ atau $(\mathrm{p}<0,05)$.

Penurunan nilai rerata keluhan subjektif yang dirasakan subjek sebelum dan sesudah menggunakan alat penopang kepala. Hal ini disebabkan karena sebelumnya terjadi pembebanan otot satatik pada leher dan sikap paksa tekanan pada kepala, tetapi sesudah menggunakan alat penopang kepala pembebanan otot statik leher dan sikap paksa tekanan pada kepala secara berlebihan dapat dihindari. Jadi buruh suwun dalam melakukan aktivitasnya beban sebagai stressor tidak lagi berpusat pada kepala dan leher, tetapi bertumpu dan berpusat pada bahu kiri dan kanan. Keuntungan lainnya bilamana buruh suwun menggunakan alat penopang 
kepala tersebut adalah yang bersangkutan dapat menoleh ke kiri kanan serta melihat ke arah atas bawah tanpa merubah posisi beban (statis). Sikap berdiri untuk waktu yang cukup lama dan pembebanan otot statis akibat sikap kerja paksa menyebabkan terjadinya bendungan darah vena, penimbunan cairan dan varises pada kaki dan sering dirasakan sebagai kelelahan otot ${ }^{12}$.

Dalam Penelitian ini bila keadaan kerja alamiah terlihat otot skeletal buruh suwun pada lehernya yang tegang terus menerus, hal ini dapat menyebabkan terjadinya penimbunan sisa metabolisme. Sementara sikap kerja menggunakan alat penopang kepala boleh diterapkan, dimana kerja otot skeletal pada leher lebih dinamis dan tidak sampai terjadi sikap paksa. Peredaran darah yang membawa oksigen ke bagian-bagian otot skeletal terutama pada leher dan kepala akan terus mengalir, sehingga tidak sampai terjadi penimbunan asam laktat dan panas tubuh. Dengan demikian buruh suwun yang menggunakan alat penopang kepala dapat mengurangi beban kerja dan keluhan subjektif yan dirasakan, serta memberi manfaat lebih lancar dalam berlalu-lintas di dalam pasar, seperti naik atau turun tangga, menyeberang dan melakukan komunikasi. Alat penopang kepala selain memiliki manfaat, tapi ada juga kelemahannya, yaitu harus didesain berdasarkan antropometri individu buruh suwun, dimana tinggi badan bisa sama namun proporsi antara tinggi bahu dengan puncak kepala bisa berbeda-beda. Begitu pula dengan kemampuan dan kecepatan beradaptasi masing-masing individu buruh suwun terhadap penerimaan sesuatu alat yang baru terutama yang berhubungan dengan kenyamanan, estetika serta kemudahan dalam memakainya. Terhadap kelemahan daripada alat penopang kepala tersebut, disarankan kepada Dinas Tenaga Kerja Kota Denpasar agar terus melakukan uji coba dan sosialisasi alat penopang kepala kepada tukang suwun. Kepada peneliti lainnya disarankan agar dapat melanjutkan dan mengembangkan penelitian ini dengan menciptakan alat penopang kepala yang lebih inovatif 
dan modern untuk masa yang akan datang.

\section{SIMPULAN}

Ada perbedaan denyut nadi kerja buruh suwun sebelum dan sesudah bekerja menggunakan alat penopang kepala $(\mathrm{p}<0,05)$ dan ada perbedaan keluhan subjektif yang dirasakan buruh suwun sebelum dan sesudah bekerja menggunakan alat penopang kepala $(\mathrm{p}<0,05)$.

\section{SARAN}

Kepada Dinas Tenaga Kerja Kota Denpasar selaku Penanggung Jawab tenaga kerja informal agar terus melakukan uji coba dan sosialisasi alat penopang kepala kepada buruh suwun di Pasar Badung dan kepada peneliti lain disarankan untuk menggunakan jumlah sampel yang lebih besar dan melakukan penelitian untuk menciptakan alat penopang kepala yang lebih inovasif dan modern.

\section{DAFTAR PUSTAKA}

1. Cahyani, W. D. Hubungan Antara Beban Kerja Dengan Kelelahan Kerja Pada Pekerja Buruh Angkut. Pena J. Ilmu Pengetah. dan Teknol. 19, (2010).

2. Chung, Y. . Risk of musculoskeletal disorder among Taiwanese nurses cohort: a nationwide population-based study. BMC Musculoskelet.

Disord. 14, (2013).

3. Hutagalung, R. Perbaikan Kualitas Kerja Dengan Menerapkan Pendekatan Ergonomi Meningkatkan Kinerja Buruh Angkat -Angkut Tradisional di Pasar Badung Denpasar. (Universitas Udayana, 2009).

4. As'adi, S. \& P. Hubungan antara Karakteristik Individu dan Manual Material Handling dengan Keluhan Muskuloskeletal Akibat Kerja. e-Jurnal Pustaka Kesehat. 2, 271-276 (2014). 
5. Notoatmodjo. Metodelogi

Penelitian KesehataN. (Rineka

Cipta, 2005).

6. Nurmianto. Ergonomi : Konsep

Dasar dan Aplikasinya. (PT

Guna Widya, 2004).

7. Andewi, P. J. Perbaikan Sikap

Kerja dengan Memakai Kursi

dan Meja Kerja Sesuai Data

Antropometri Pekerja dapat

Meningkatkan Produktivitas

Kerja \& Mengurangi Gangguan

Sistem Muskuloskeleta

Perusahaan MI. (Universitas

Udayana, 1999).

8. Purnawan, I. Perbaikan Sikap

Kerja Mengurangi Keluhan

Subjektif Perajin Layang-layang

Home Industri di Sanur.

Surabaya. (PT. Guna Widya,

2000).

9. Susilowati, S. Pengaruh Posisi

Kerja Terhadap Produktivitas

dan Keluhan Subjektif

Karyawan. (PT Guna Widya,

2000).

10. Adiputra, N. Denyut Nadi dan
Kegunaannya Dalam Ergonomi.

J. Ergon. Indones. 3, 22-26

(2002).

11. Brage, S. Musculoskeletal Pain and Smoking in Norway. $J$. Epidemiol. Community Health 50, 166-169 (1996).

12. Pheasant, S. Ergonomik Work and Health. Mac Millan Acad. Prof. Ltd. London (1991). 